\title{
Macronutrients, Micronutrients, and Global Nutrient Database
}

\section{Attapon Cheepsattayakorn ${ }^{1,2 *}$, Ruangrong Cheepsattayakorn ${ }^{3}$ and Utoomporn Sittisingh ${ }^{2}$}

${ }^{1} 10^{\text {th }}$ Zonal Tuberculosis and Chest Disease Center, Chiang Mai, Thailand

${ }^{2}$ St. Theresa International College, Nakorn Nayok, Thailand

${ }^{3}$ Department of Pathology, Faculty of Medicine, Chiang Mai University, Chiang Mai,

Thailand

*Corresponding Author: Attapon Cheepsattayakorn, 10th Zonal Tuberculosis

and Chest Disease Center, Chiang Mai, Thailand.

DOI: 10.31080/ASNH.2020.04.0651

As long as the metabolic events continue, all living beings need more than 50 nutrients or chemical compounds and energy to live. Energy is spent every day at rest (basal metabolism) and during physical activity. Basal metabolism is required to restore the basic function of the body, such as respiration, heartbeat, etc. through metabolic pathways that are regulated by minerals, vitamins, hormones, and enzymes. Every nutrient group should be identified in balanced diet. During daily feeding, nutrients that are taken in a lot quantities are macronutrients, whereas micronutrients are nutrients that human's body needs in lesser quantities. Macronutrients are classified into three types, carbohydrates, proteins, and fats, whereas micronutrients are classified into three building blocks, glucose, amino acid, and fatty acid. Carbohydrates are classified into 2 types, monosaccharides (glucose, fructose, galactose) and disaccharides (sucrose, lactose, maltose). Polysaccharides are polymers formed by the combination of a large number of monosaccharide monomers, such as starch, glycogen, cellulose, inulin, and pectin. Micronutrients are classified as vitamins, water soluble vitamins, minerals, and water.

A previous study on macronutrients and micronutrients in 195 countries between 1980 and 2013 demonstrated that globally $2710 \mathrm{kcal}(95 \%$ UI 2,660 - 2,770) were available per person per day in 2013. Carbohydrates were the major contributor to energy availability (70.5\%), followed by fats (17.4\%), and protein $(10.5 \%)$. Countries at the higher level of development or high Socio-demographic Index countries had more energy available per person per day (3270 kcal, 3220 - 3310); greater contributions from fats $(26.0 \%)$ and proteins $(11.9 \%)$ to total energy availability; and lower contributions from carbohydrate (54.8\%). During 1980 - 2013, the supply of the micronutrients has increased globally and across levels of development. During the same period, energy availability and the contributions of protein and fats to energy availability have globally increased and across levels of development whereas the contribution of carbohydrates to total energy availability has decreased.

In conclusion, if individuals consume a single food group, they can get both macronutrients and micronutrients at the same time. Fresh foods always contain much more micronutrients than pro- cessed foods, whereas processed and high-calorie foods contain high amount of macronutrients, such as fried foods, refined grains, sweet, poor quality meat, and poor dairy products that contain low quantities of micronutrients.

\section{Assets from publication with us}

- Prompt Acknowledgement after receiving the article

- Thorough Double blinded peer review

- Rapid Publication

- Issue of Publication Certificate

- High visibility of your Published work

Website: https://www.actascientific.com/

Submit Article: https://www.actascientific.com/submission.php Email us: editor@actascientific.com

Contact us: +919182824667 